\title{
On fixed point theory in partial metric spaces
}

\author{
Maryam A Alghamdi ${ }^{1}$, Naseer Shahzad ${ }^{2 *}$ and Oscar Valero ${ }^{3}$
}

${ }^{\text {"Correspondence: }}$

nshahzad@kau.edu.sa

${ }^{2}$ Department of Mathematics, King Abdulaziz University, P.O. Box 80203

Jeddah, 21859, Saudi Arabia

Full list of author information is

available at the end of the article

\begin{abstract}
In this paper, we continue the study of contractive conditions for mappings in complete partial metric spaces. Concretely, we present fixed point results for weakly contractive and weakly Kannan mappings in such a way that the classical metric counterpart results are retrieved as a particular case. Special attention to the cyclical case is paid. Moreover, the well-posedness of the fixed point problem associated to weakly (cyclic) contractive and weakly (cyclic) Kannan mappings is discussed, and it is shown that these contractive mappings are both good Picard operators and special good Picard operators.
\end{abstract}

\section{Introduction}

Throughout this paper, the letters $\mathbb{R}, \mathbb{R}_{+}, \mathbb{N}$ and $\mathbb{Z}_{+}$will denote the set of real numbers, the set of nonnegative real numbers, the set of positive integer numbers and the set of nonnegative integer numbers, respectively.

The celebrated fixed point theorem of Banach asserts the following.

Theorem 1 If $(X, d)$ is a complete metric space and $f: X \rightarrow X$ is a mapping such that

$$
d(f(x), f(y)) \leq \alpha d(x, y)
$$

for all $x, y \in X$ and some $\alpha \in\left[0,1\left[\right.\right.$, then $f$ has a unique fixed point $x^{*} \in X$. Moreover, the Picard sequence of iterates $\left\{f^{n}(x)\right\}_{n \in \mathbb{N}}$ converges, for every $x \in X$, to $x^{*}$.

In [1], Kannan obtained the following extension of the aforementioned fixed point theorem of Banach to a larger class of mappings, now known as Kannan mappings.

Theorem 2 Let $(X, d)$ be a complete metric space and let $f: X \rightarrow X$ be a mapping such that

$$
d(f(x), f(y)) \leq \frac{\alpha}{2}[d(x, f(x))+d(y, f(y))]
$$

for all $x, y \in X$ and some $\alpha \in\left[0,1\left[\right.\right.$, then $f$ has a unique fixed point $x^{*} \in X$. Moreover, the Picard sequence of iterates $\left\{f^{n}(x)\right\}_{n \in \mathbb{N}}$ converges, for every $x \in X$, to $x^{*}$.

Another extensions of Banach's fixed point theorem were given by Kirk, Srinivasan and Veeramani in [2]. They obtained general fixed point theorems for mappings satisfying cyclical contractive conditions. Among other results, the following one was proven in [2].

(c) 2012 Alghamdi et al.; licensee Springer. This is an Open Access article distributed under the terms of the Creative Commons Attribution License (http://creativecommons.org/licenses/by/2.0), which permits unrestricted use, distribution, and reproduction in any medium, provided the original work is properly cited. 
Theorem 3 Let $A_{1}, \ldots, A_{m}$ be a collection of nonempty closed subsets of a complete metric space $(X, d)(m \in \mathbb{N}$ and $m>1)$. Suppose that there exists $\alpha \in[0,1[$ such that a mapping $f: \bigcup_{i=1}^{m} A_{i} \rightarrow \bigcup_{i=1}^{m} A_{i}$ satisfies the following conditions:

(1) $f\left(A_{i}\right) \subseteq A_{i+1}$ for all $1 \leq i \leq m$, where $A_{m+1}=A_{1}$;

(2) $d(f(x), f(y)) \leq \alpha d(x, y)$ for all $x \in A_{i}, y \in A_{i+1}$ and $1 \leq i \leq m$.

Then $f$ has a unique fixed point $x^{*} \in \bigcap_{i=1}^{m} A_{i}$ and the Picard sequence of iterates $\left\{f^{n}(x)\right\}_{n \in \mathbb{N}}$ converges, for every $x \in X$, to $x^{*}$.

Since Kirk, Srinivasan and Veeramani gave the aforementioned generalizations, intensive research on this topic has provided a wide number of works about mappings satisfying cyclical contractive conditions in metric spaces (see [3] for recent and complete bibliography). In particular, in [4] the following fixed point theorem, which generalizes the aforesaid Kannan fixed point theorem (Theorem 2), for Kannan cyclical contractive mappings was proved.

Theorem 4 Let $A_{1}, \ldots, A_{m}$ be a collection of nonempty closed subsets of a complete metric space $(X, d)(m \in \mathbb{N}$ and $m>1)$. Suppose that there exists $\alpha \in[0,1[$ such that a mapping $f: \bigcup_{i=1}^{m} A_{i} \rightarrow \bigcup_{i=1}^{m} A_{i}$ satisfies the following conditions:

(1) $f\left(A_{i}\right) \subseteq A_{i+1}$ for all $1 \leq i \leq m$, where $A_{m+1}=A_{1}$;

(2) $d(f(x), f(y)) \leq \frac{\alpha}{2}[d(x, f(x))+d(y, f(y))]$ for all $x \in A_{i}, y \in A_{i+1}$ and $1 \leq i \leq m$.

Then $f$ has a unique fixed point $x^{*} \in \bigcap_{i=1}^{m} A_{i}$ and the Picard sequence of iterates $\left\{f^{n}(x)\right\}_{n \in \mathbb{N}}$ converges, for every $x \in X$, to $x^{*}$.

Recently, a large number of fixed point results in the metric context, including Theorems 1, 2, 3 and 4, have been extended to the framework of partial metric spaces. Let us recall that the notion of partial metric space was introduced by Matthews in 1994 as a part of the study of denotational semantics of dataflow networks (see [5] and [6]) and that, thenceforth, partial metric spaces play an important role in constructing models in the theory of computation (for a fuller treatment we refer the reader to [7-12] and [13]).

Let us recall some pertinent definitions of partial metric spaces and some of their properties which can be found in [5].

Definition 5 A partial metric on a nonempty set $X$ is a function $p: X \times X \rightarrow \mathbb{R}_{+}$such that for all $x, y, z, \in X$ :

$\left(\mathrm{p}_{1}\right) x=y \Leftrightarrow p(x, x)=p(x, y)=p(y, y)$,

$\left(\mathrm{p}_{2}\right) p(x, x) \leq p(x, y)$

(р $\left.\mathrm{p}_{3}\right) p(x, y)=p(y, x)$,

$\left(\mathrm{p}_{4}\right) p(x, y) \leq p(x, z)+p(z, y)-p(z, z)$.

A partial metric space is a pair $(X, p)$ such that $X$ is a nonempty set and $p$ is a partial metric on $X$.

Note that from the preceding definition, concretely from statements $\left(\mathrm{p}_{1}\right)$ and $\left(\mathrm{p}_{2}\right)$, it follows that $p(x, y)=0$ implies that $x=y$. However, in general, the fact that $x=y$ does not necessarily imply that $p(x, y)=0$. A typical example of this situation is provided by the partial metric space $\left(\mathbb{R}_{+}, p_{\max }\right)$, where the function $p_{\max }: \mathbb{R}_{+} \times \mathbb{R}_{+} \rightarrow \mathbb{R}_{+}$is defined by $p_{\max }(x, y)=\max \{x, y\}$ for all $x, y \in \mathbb{R}_{+}$. 
Other examples of partial metric spaces which are interesting from a computational point of view may be found in [14] and [5]. According to [5], each partial metric $p$ on $X$ generates a $T_{0}$ topology $\tau(p)$ on $X$ which has as a base the family of open $p$-balls $\left\{B_{p}(x, \varepsilon)\right.$ : $x \in X, \varepsilon>0\}$, where $B_{p}(x, \varepsilon)=\{y \in X: p(x, y)<p(x, x)+\varepsilon\}$ for all $x \in X$ and $\varepsilon>0$. From the preceding fact it immediately follows that a sequence $\left\{x_{n}\right\}_{n \in \mathbb{N}}$ in a partial metric space $(X, p)$ converges to a point $x \in X$ if and only if $p(x, x)=\lim _{n \rightarrow \infty} p\left(x, x_{n}\right)$.

Following [5], a sequence $\left\{x_{n}\right\}_{n \in \mathbb{N}}$ in a partial metric space $(X, p)$ is called a Cauchy sequence if $\lim _{n, m \rightarrow \infty} p\left(x_{n}, x_{m}\right)$ exists and is finite. Moreover, a partial metric space $(X, p)$ is said to be complete if every Cauchy sequence $\left\{x_{n}\right\}_{n \in \mathbb{N}}$ in $X$ converges, with respect to $\tau(p)$, to a point $x \in X$ such that $p(x, x)=\lim _{n, m \rightarrow \infty} p\left(x_{n}, x_{m}\right)$. An easy, but illustrative, example of complete partial metric space is given by the pair $\left(\mathbb{R}_{+}, p_{\max }\right)$.

It is known (see [5]) that if $p$ is a partial metric on $X$, then the function $p^{s}: X \times X \rightarrow \mathbb{R}_{+}$ given for all $x, y \in X$ by

$$
p^{s}(x, y)=2 p(x, y)-p(x, x)-p(y, y)
$$

is a metric on $X$.

Taking into account the preceding interesting relationship between partial metrics and metrics, the following useful remarks were introduced in [5] (compare [15]).

If a sequence converges in a partial metric space $(X, p)$ with respect to $\tau\left(p^{s}\right)$, then it converges with respect to $\tau(p)$. Of course, the converse is not true.

A sequence $\left\{x_{n}\right\}_{n \in \mathbb{N}}$ in a partial metric space $(X, p)$ is Cauchy if and only if it is a Cauchy sequence in the metric space $\left(X, p^{s}\right)$. Moreover, a partial metric space $(X, p)$ is complete if and only if the metric space $\left(X, p^{s}\right)$ is complete. Furthermore, given a sequence $\left\{x_{n}\right\}_{n \in \mathbb{N}}$ in a partial metric space $(X, p)$ and $x \in X$, one has that

$$
\lim _{n \rightarrow \infty} p^{s}\left(x, x_{n}\right)=0 \Leftrightarrow p(x, x)=\lim _{n \rightarrow \infty} p\left(x, x_{n}\right)=\lim _{n, m \rightarrow \infty} p\left(x_{n}, x_{m}\right)
$$

In [5], Matthews obtained a generalization of Banach's fixed point theorem for partial metric spaces that can be stated as follows.

Theorem 6 Let $(X, p)$ be a complete partial metric space and let $f: X \rightarrow X$ be a mapping such that there exists $\alpha \in[0,1[$ satisfying

$$
p(f(x), f(y)) \leq \alpha p(x, y)
$$

for all $x, y \in X$. Then $f$ has a unique fixed point $x^{*} \in X$. Moreover, $p\left(x^{*}, x^{*}\right)=0$ and the Picard sequence of iterates $\left\{f^{n}(x)\right\}_{n \in \mathbb{N}}$ converges with respect to $\tau\left(p^{s}\right)$, for every $x \in X$, to $x^{*}$.

As noted above, an intense research activity on fixed point results in partial metric spaces has been developed in the past years. Thus, a large number of fixed point results in the metric framework have been extended to the partial metric case in such references as $[9,16-40]$ and [41].

Inspired by the interest aroused by fixed point theory in partial metric spaces, in the present paper, we focus our study on the possibility of extending some metric fixed point theorems for the so-called weakly contractive mappings and weakly Kannan mappings to the context of partial metric spaces. 
Let us recall, for the sake of completeness, the both aforementioned notions in the metric framework.

Definition 7 [42] Let $(X, d)$ be a metric space. A mapping $f: X \rightarrow X$ is said to be weakly contractive provided that

$$
d(f(x), f(y)) \leq \bar{\alpha}(x, y) d(x, y)
$$

for all $x, y \in X$, where the function $\bar{\alpha}: X \times X \rightarrow[0,1[$ holds, for every $0<a \leq b$, that

$$
\theta(a, b)=\sup \{\bar{\alpha}(x, y): a \leq d(x, y) \leq b\}<1
$$

Observe that the contractive condition in Definition 7, due to Dugundji and Granas, is mainly based on replacing the constant $\alpha$ in (1.1) (see Theorem 1) by the function $\bar{\alpha}$.

Definition 8 [43] Let $(X, d)$ be a metric space. A mapping $f: X \rightarrow X$ is said to be weakly Kannan if there exists $\bar{\alpha}: X \times X \rightarrow[0,1[$ which satisfies for every $0<a \leq b$ and for all $x, y \in X$ that

$$
\theta(a, b)=\sup \{\bar{\alpha}(x, y): a \leq d(x, y) \leq b\}<1
$$

and

$$
d(f(x), f(y)) \leq \frac{\bar{\alpha}(x, y)}{2}[d(x, f(x))+d(y, f(y))] .
$$

Observe that the class of mappings, introduced by Ariza-Ruiz and Jimenez-Melando, in Definition 8 is larger than the class of Kannan mappings (i.e., mappings satisfying inequality (1.2) in Theorem 2) such as Example 2.5 in [43] shows.

According to the exposed notions, the following fixed point theorems were proved in [42] and [43], respectively.

Theorem 9 Let $(X, d)$ be a complete metric space. If $f: X \rightarrow X$ is a weakly contractive mapping, then $f$ has a unique fixed point $x^{*}$ and the Picard sequence of iterates $\left\{f^{n}(x)\right\}_{n \in \mathbb{N}}$ converges, for every $x \in X$, to $x^{*}$.

Theorem 10 Let $(X, d)$ be a complete metric space. Iff $: X \rightarrow X$ is a weakly Kannan mapping, then $f$ has a unique fixed point $x^{*}$ and the Picard sequence of iterates $\left\{f^{n}(x)\right\}_{n \in \mathbb{N}}$ converges, for every $x \in X$, to $x^{*}$.

As we have mentioned before, we are interested in extending metric fixed point theorems for the so-called weakly contractive mappings and weakly Kannan mappings to the context of partial metric spaces. In particular, and in the light of the both previous results, our objective in this paper is threefold. We introduce the notions of a weakly contractive mapping and a weakly Kannan mapping in the partial metric framework, and we present a partial metric version of Theorems 9 and 10 in such a way that both aforesaid results are retrieved as a particular case when the partial metric is, in fact, a metric. Moreover, motivated in part by the fact that we have not come across a version of Theorems 9 and 10 
for the cyclical case in the literature, we prove a cyclical version of both preceding results in the partial metric context providing, as a particular case of our new results, the not found cyclical version of Theorems 9 and 10 for the classical case when we consider again that the partial metric is a metric. Finally, we show the well-posedness of our new fixed point results in the sense of [39] (and also [44]) and, in addition, we prove that the new contractive mappings are good Picard operators and special Picard operators in the spirit of Rus ([45]).

\section{Main results}

\subsection{Weakly contractive and weakly Kannan mappings in complete partial metric spaces: new fixed point results}

In this subsection, we prove an extension of Theorems 9 and 10 in complete partial metric spaces. To do this, we first extend the notions of a weakly contractive mapping and a weakly Kannan mapping to our new context.

Definition 11 Let $(X, p)$ be a partial metric space. A mapping $f: X \rightarrow X$ is said to be weakly contractive provided that there exists $\bar{\alpha}: X \times X \rightarrow[0,1[$ such that for every $0 \leq$ $a \leq b$,

$$
\theta(a, b)=\sup \{\bar{\alpha}(x, y): a \leq p(x, y) \leq b\}<1
$$

and for all $x, y \in X$,

$$
p(f(x), f(y)) \leq \bar{\alpha}(x, y) p(x, y) .
$$

Notice that if there exists $\alpha \in[0,1[$ such that the function $\bar{\alpha}$ given in Definition 11 holds $\bar{\alpha}(x, y)=\alpha$ for all $x, y \in X$, then we retrieve, as a particular case of our notion, the contractive one given by Matthews in [5].

Definition 12 Let $(X, p)$ be a partial metric space. A mapping $f: X \rightarrow X$ is said to be weakly Kannan if there exists $\bar{\alpha}: X \times X \rightarrow[0,1$ [ which satisfies for every $0 \leq a \leq b$ and for all $x, y \in X$ that

$$
\theta(a, b)=\sup \{\bar{\alpha}(x, y): a \leq p(x, y) \leq b\}<1
$$

and

$$
p(f(x), f(y)) \leq \frac{\bar{\alpha}(x, y)}{2}[p(x, f(x))+p(y, f(y))] .
$$

Of course when the function $\bar{\alpha}$ satisfies that there exists $\alpha \in[0,1[$ such that $\bar{\alpha}(x, y)=\alpha$ for all $x, y \in X$, we say that the mapping $f$ is a Kannan mapping.

Observe that when the partial metric is exactly a metric, we obtain as a particular case of our new notions those given in Definitions 7 and 8 and in Theorem 2.

The next example shows that there exist weakly contractive mappings in the sense of Definition 11 that are not weakly contractive mappings in the sense of Definition 7. 
Example 13 Let $\left.p_{\max }\right|_{[0,1]}$ represent the restriction of the partial metric $p_{\max }$ on $\mathbb{R}_{+}$(introduced in Section 1$)$ to the set $[0,1]$. Consider the partial metric space $\left([0,1], p_{\max } \mid[0,1]\right)$.

Define the function $f:[0,1] \rightarrow[0,1]$ by

$$
f(x)=\frac{x^{2}}{2}
$$

for all $x \in[0,1]$, and the function $\bar{\alpha}:[0,1] \times[0,1] \rightarrow[0,1[$ by

$$
\bar{\alpha}(x, y)=\frac{1}{2}
$$

for all $x, y \in[0,1]$.

It is immediate to check that the function $\bar{\alpha}$ holds the requirements in Definition 11, that is, $\theta(a, b)<1$ for every $0 \leq a \leq b$.

It is routine to verify that the function $f$ is a weakly contractive function, i.e., that

$$
\left.p_{\max }\right|_{[0,1]}(f(x), f(y)) \leq\left.\bar{\alpha}(x, y) p_{\max }\right|_{[0,1]}(x, y)
$$

for all $x, y \in[0,1]$. Observe that, in fact, the function $f$ is contractive in the sense of Matthews (see Theorem 6) since $\bar{\alpha}(x, y)=\frac{1}{2}$ for all $x, y \in[0,1]$.

However, the function $f$ is not a weakly contractive function with respect to the metric $\left.p_{\max }\right|_{[0,1]} ^{s}$ (i.e., that $f$ is not weakly contractive with respect to the metric $\left.p_{\max }\right|_{[0,1]} ^{s}$ for any choice of a function $\bar{\alpha}$ satisfying all the requirements in Definition 7). Indeed, assume for the purpose of contradiction that there exists $\bar{\alpha}:[0,1] \times[0,1] \rightarrow[0,1[$ satisfying the requirements in Definition 7 such that

$$
\left|\frac{x^{2}}{2}-\frac{y^{2}}{2}\right| \leq \bar{\alpha}(x, y)|x-y|
$$

for all $x, y \in[0,1]$ (note that $p_{\max }^{s}(x, y)=|x-y|$ for all $\left.x, y \in[0,1]\right)$. Then we obtain that

$$
\frac{x+y}{2} \leq \bar{\alpha}(x, y)
$$

for all $x, y \in[0,1]$. Whence we deduce that $1 \leq \bar{\alpha}(1,1)<1$, which provides a contradiction.

In the following example, we show that there exist mappings that are weakly Kannan mappings in the sense of Definition 12 that are not weakly Kannan mappings in the sense of Definition 8.

Example 14 Consider the partial metric space $\left([0,1],\left.p_{\max }\right|_{[0,1]}\right)$ and the function $f$ : $[0,1] \rightarrow[0,1]$ given by

$$
f(x)=\frac{x^{2}}{x+1}
$$

for all $x \in[0,1]$. Define the function $\bar{\alpha}:[0,1] \times[0,1] \rightarrow[0,1[$ by

$$
\bar{\alpha}(x, y)= \begin{cases}\frac{\left.p_{\max }\right|_{[0,1]}(f(x), f(y))}{p_{\max }[0,1](x, y)} & \text { if } \max \{x, y\} \neq 0, \\ 0 & \text { if } \max \{x, y\}=0\end{cases}
$$


for all $x, y \in[0,1]$. It is clear that $\bar{\alpha}(x, y) \leq \frac{1}{2}$ for all $x, y \in[0,1]$. Whence we immediately deduce that the function $\bar{\alpha}$ holds all the requirements in Definition 12, i.e., $\theta(a, b)<1$ for every $0 \leq a \leq b$. Moreover, it is a simple matter to show that $f$ is a weakly Kannan mapping, i.e.,

$$
\left.p_{\max }\right|_{[0,1]}(f(x), f(y)) \leq \frac{\bar{\alpha}(x, y)}{2}\left[\left.p_{\max }\right|_{[0,1]}(x, f(x))+\left.p_{\max }\right|_{[0,1]}(y, f(y))\right]
$$

for all $x, y \in[0,1]$. Nevertheless, the function $f$ is not a weakly Kannan mapping in the sense of Definition 8 with respect to the metric $\left.p_{\max }\right|_{[0,1]} ^{s}$ (i.e., that $f$ is not weakly Kannan with respect to the metric $\left.p_{\max }\right|_{[0,1]} ^{s}$ for any choice of a function $\bar{\alpha}$ satisfying all the requirements in Definition 8). To see this, take $x=1$ and $y=0$. Assume for the purpose of contradiction that there exists $\bar{\alpha}:[0,1] \times[0,1] \rightarrow[0,1[$ which holds all the requirements in Definition 8 . Then

$$
\frac{1}{2}=|f(1)-f(0)| \leq \frac{\bar{\alpha}(1,0)}{2}[|1-f(1)|+|0-f(0)|]=\frac{\bar{\alpha}(1,0)}{4} .
$$

It follows that $2 \leq \bar{\alpha}(1,0)$, which contradicts the fact that $\bar{\alpha}(x, y) \leq 1$ for all $x, y \in[0,1]$.

In order to present the announced partial metric versions of Theorem 9 and Theorem 10 , we prove the following fixed point result where we introduce a contractive condition which mixes the contractive conditions in Definitions 11 and 12.

Theorem 15 Let $(X, p)$ be a complete partial metric space and let $f: X \rightarrow X$ be a mapping such that there exists $\bar{\alpha}: X \times X \rightarrow[0,1]$ with

$$
\theta(a, b)=\sup \{\bar{\alpha}(x, y): a \leq p(x, y) \leq b\}<1
$$

for every $0 \leq a \leq b$, and such that

$$
p(f(x), f(y)) \leq \bar{\alpha}(x, y) \max \left\{p(x, y), \frac{1}{2}[p(x, f(x))+p(y, f(y))]\right\}
$$

for all $x, y \in X$. Then $f$ has a unique fixed point $x^{*} \in X$ and the Picard sequence of iterates $\left\{f^{n}\left(x_{0}\right)\right\}_{n \in \mathbb{N}}$ converges with respect to $\tau\left(p^{s}\right)$, for every $x_{0} \in X$, to $x^{*}$. Moreover, $p\left(x^{*}\right.$, $\left.x^{*}\right)=0$.

Proof Consider $x_{0} \in X$ and define the Picard sequence of iterates by

$$
x_{n}=f\left(x_{n-1}\right)=f^{n}\left(x_{0}\right) \quad(n \in \mathbb{N}) .
$$

Assume $x_{n} \neq x_{n+1}$ for all $n \in \mathbb{N}$ because otherwise we have the existence of a fixed point guaranteed. By (2.1), we have

$$
\begin{aligned}
p\left(x_{n}, x_{n+1}\right) & =p\left(f\left(x_{n-1}\right), f\left(x_{n}\right)\right) \\
& \leq \bar{\alpha}\left(x_{n-1}, x_{n}\right) M\left(x_{n-1}, x_{n}\right),
\end{aligned}
$$


where

$$
\begin{aligned}
M\left(x_{n-1}, x_{n}\right) & =\max \left\{p\left(x_{n-1}, x_{n}\right), \frac{1}{2}\left[p\left(x_{n-1}, f\left(x_{n-1}\right)\right)+p\left(x_{n}, f\left(x_{n}\right)\right)\right]\right\} \\
& =\max \left\{p\left(x_{n-1}, x_{n}\right), \frac{1}{2}\left[p\left(x_{n-1}, x_{n}\right)+p\left(x_{n}, x_{n+1}\right)\right]\right\} .
\end{aligned}
$$

Now, we prove that for all $n \in \mathbb{N}$, the following inequality holds:

$$
p\left(x_{n}, x_{n+1}\right) \leq \bar{\alpha}\left(x_{n-1}, x_{n}\right) p\left(x_{n-1}, x_{n}\right) .
$$

We consider the following two cases:

Case 1. If $M\left(x_{n-1}, x_{n}\right)=p\left(x_{n-1}, x_{n}\right)$, then

$$
p\left(x_{n}, x_{n+1}\right) \leq \bar{\alpha}\left(x_{n-1}, x_{n}\right) p\left(x_{n-1}, x_{n}\right) .
$$

Case 2. If $M\left(x_{n-1}, x_{n}\right)=\frac{1}{2}\left[p\left(x_{n-1}, x_{n}\right)+p\left(x_{n}, x_{n+1}\right)\right]$, then

$$
p\left(x_{n}, x_{n+1}\right) \leq \frac{\bar{\alpha}\left(x_{n-1}, x_{n}\right)}{2}\left[p\left(x_{n-1}, x_{n}\right)+p\left(x_{n}, x_{n+1}\right)\right]
$$

and so

$$
\left(1-\frac{\bar{\alpha}\left(x_{n-1}, x_{n}\right)}{2}\right) p\left(x_{n}, x_{n+1}\right) \leq \frac{\bar{\alpha}\left(x_{n-1}, x_{n}\right)}{2} p\left(x_{n-1}, x_{n}\right)
$$

i.e.,

$$
\begin{aligned}
p\left(x_{n}, x_{n+1}\right) & \leq \frac{\bar{\alpha}\left(x_{n-1}, x_{n}\right)}{2-\bar{\alpha}\left(x_{n-1}, x_{n}\right)} p\left(x_{n-1}, x_{n}\right) \\
& \leq \bar{\alpha}\left(x_{n-1}, x_{n}\right) p\left(x_{n-1}, x_{n}\right) .
\end{aligned}
$$

Then (2.2) holds for all $n \in \mathbb{N}$. It follows that the sequence $\left\{p\left(x_{n}, x_{n+1}\right)\right\}_{n \in \mathbb{N}}$ is nonincreasing since $0 \leq \bar{\alpha}\left(x_{n-1}, x_{n}\right) \leq 1$, and then it is convergent to a real number

$$
p=\inf \left\{p\left(x_{n-1}, x_{n}\right): n \in \mathbb{N}\right\} .
$$

For the purpose of contradiction, assume that $p>0$. Then for all $n \in \mathbb{N}$, we have

$$
0<p \leq p\left(x_{n}, x_{n+1}\right) \leq p\left(x_{n-1}, x_{n}\right) \leq \cdots \leq p\left(x_{0}, x_{1}\right),
$$

and from the definition of $\theta=\theta\left(p, p\left(x_{0}, x_{1}\right)\right)$, we obtain that $\bar{\alpha}\left(x_{n-1}, x_{n}\right) \leq \theta$. Thus,

$$
p \leq p\left(x_{n}, x_{n+1}\right) \leq \bar{\alpha}\left(x_{n-1}, x_{n}\right) p\left(x_{n-1}, x_{n}\right) \leq \theta^{n} p\left(x_{0}, x_{1}\right)
$$

for all $n \in \mathbb{N}$. Whence we obtain a contradiction since $0 \leq \theta<1$, and hence $\lim _{n \rightarrow \infty} \theta^{n}=0$. Therefore, $p=0$ and $\lim _{n \rightarrow \infty} p\left(x_{n}, x_{n+1}\right)=0$. This last fact implies, in turn, that 
$\lim _{n \rightarrow \infty} p^{s}\left(x_{n}, x_{n+1}\right)=0$ since $p^{s}\left(x_{n}, x_{n+1}\right) \leq 2 p\left(x_{n}, x_{n+1}\right)$ for all $n \in \mathbb{N}$. Moreover, since for all $n \in \mathbb{N}$,

$$
p\left(x_{n}, x_{n}\right) \leq p\left(x_{n}, x_{n+1}\right)
$$

we obtain that $\lim _{n \rightarrow \infty} p\left(x_{n}, x_{n}\right)=0$.

For $k \in \mathbb{N}$, we have

$$
\begin{aligned}
p^{s}\left(x_{n}, x_{n+k}\right) & \leq p^{s}\left(x_{n}, x_{n+1}\right)+\cdots+p^{s}\left(x_{n+k-1}, x_{n+k}\right) \\
& \leq 2 \theta^{n} p\left(x_{0}, x_{1}\right)+\cdots+2 \theta^{n+k-1} p\left(x_{0}, x_{1}\right) \\
& \leq 2 \sum_{t=n}^{n+k-1} \theta^{t} p\left(x_{0}, x_{1}\right) \\
& \leq 2 \frac{\theta^{n}}{1-\theta} p\left(x_{0}, x_{1}\right)
\end{aligned}
$$

where $\theta=\theta\left(0, p\left(x_{0}, x_{1}\right)\right)$.

This shows that $\left\{x_{n}\right\}$ is a Cauchy sequence in the metric space $\left(X, p^{s}\right)$. Since $(X, p)$ is complete, we have that $\left(X, p^{s}\right)$ is complete. So, the sequence $\left\{x_{n}\right\}$ is convergent in the metric space $\left(X, p^{s}\right)$, say to $x^{*} \in X$, i.e., $\lim _{n \rightarrow \infty} p^{s}\left(x_{n}, x^{*}\right)=0$. It follows that

$$
p\left(x^{*}, x^{*}\right)=\lim _{n \rightarrow \infty} p\left(x_{n}, x^{*}\right)=\lim _{n, m \rightarrow \infty} p\left(x_{n}, x_{m}\right) .
$$

This shows that $\left\{x_{n}\right\}$ is a convergent sequence in $(X, p)$ with respect to $\tau\left(p^{s}\right)$.

Since $\left\{x_{n}\right\}$ is a Cauchy sequence in the metric space $\left(X, p^{s}\right)$, we have that $\lim _{n, m \rightarrow \infty} p^{s}\left(x_{n}\right.$, $\left.x_{m}\right)=0$. Moreover, from (2.4), we have $\lim _{n \rightarrow \infty} p\left(x_{n}, x_{n}\right)=0$, and then from the definition of $p^{s}$, we have $\lim _{n, m \rightarrow \infty} p\left(x_{n}, x_{m}\right)=0$. Therefore, from (2.5), we have

$$
p\left(x^{*}, x^{*}\right)=\lim _{n \rightarrow \infty} p\left(x_{n}, x^{*}\right)=\lim _{n, m \rightarrow \infty} p\left(x_{n}, x_{m}\right)=0 .
$$

Now, we prove that $p\left(x^{*}, f\left(x^{*}\right)\right)=0$. Indeed, assume that $p\left(x^{*}, f\left(x^{*}\right)\right)>0$. Then from (2.1), we have

$$
\begin{aligned}
p\left(x^{*}, f\left(x^{*}\right)\right) & \leq p\left(x^{*}, f\left(x_{n}\right)\right)+p\left(f\left(x_{n}\right), f\left(x^{*}\right)\right)-p\left(f\left(x_{n}\right), f\left(x_{n}\right)\right) \\
& \leq p\left(x^{*}, x_{n+1}\right)+p\left(f\left(x_{n}\right), f\left(x^{*}\right)\right) \\
& \leq p\left(x^{*}, x_{n+1}\right)+\bar{\alpha}\left(x_{n}, x^{*}\right) \max \left\{p\left(x_{n}, x^{*}\right), \frac{1}{2}\left[p\left(x_{n}, f\left(x_{n}\right)\right)+p\left(x^{*}, f\left(x^{*}\right)\right)\right]\right\} \\
& \leq p\left(x^{*}, x_{n+1}\right)+\max \left\{p\left(x_{n}, x^{*}\right), \frac{1}{2}\left[p\left(x_{n}, x_{n+1}\right)+p\left(x^{*}, f\left(x^{*}\right)\right)\right]\right\}
\end{aligned}
$$

for all $n \in \mathbb{N}$. Letting $n \rightarrow \infty$ in the preceding inequality, we obtain

$$
p\left(x^{*}, f\left(x^{*}\right)\right) \leq \frac{1}{2} p\left(x^{*}, f\left(x^{*}\right)\right)
$$

which is a contradiction. Whence $p\left(x^{*}, f\left(x^{*}\right)\right)=0$, and hence $p\left(f\left(x^{*}\right), f\left(x^{*}\right)\right)=0$. So, we have, by statement $\left(\mathrm{p}_{1}\right)$ in Definition 5 , that $x^{*}=f\left(x^{*}\right)$. Therefore, we have shown the ex- 
istence of a fixed point such that $p\left(x^{*}, x^{*}\right)=0$ and that the Picard sequence of iterates $\left\{f^{n}\left(x_{0}\right)\right\}_{n \in \mathbb{N}}$ converges to $x^{*}$ with respect to $\tau\left(p^{s}\right)$.

To conclude the proof, we only need to prove that uniqueness of a fixed point. To this end, suppose for the purpose of contradiction that there exists another fixed point $z \in X$ of $f$ with $z \neq x^{*}$. Thus, $r=p\left(x^{*}, z\right)>0$, and we immediately obtain

$$
\alpha\left(x^{*}, z\right) \leq \theta\left(\frac{r}{2}, r\right)<1,
$$

where $r=p\left(x^{*}, z\right)>0$. Now, by $(2.1)$ and by the fact that

$$
0=p\left(x^{*}, x^{*}\right)<p\left(x^{*}, z\right) \text { and } p(z, z) \leq p\left(x^{*}, z\right)
$$

we have

$$
\begin{aligned}
p\left(x^{*}, z\right) & =p\left(f\left(x^{*}\right), f(z)\right) \\
& \leq \bar{\alpha}\left(x^{*}, z\right) \max \left\{p\left(x^{*}, z\right), \frac{1}{2}\left[p\left(x^{*}, f\left(x^{*}\right)\right)+p(z, f(z))\right]\right\} \\
& =\bar{\alpha}\left(x^{*}, z\right) \max \left\{p\left(x^{*}, z\right), \frac{1}{2}\left[p\left(x^{*}, x^{*}\right)+p(z, z)\right]\right\} \\
& \leq \bar{\alpha}\left(x^{*}, z\right) p\left(x^{*}, z\right) \\
& \leq \theta\left(\frac{r}{2}, r\right) p\left(x^{*}, z\right),
\end{aligned}
$$

which is a contradiction. Thus, $x^{*}=z$.

As a consequence of the preceding theorem, we obtain the following one.

Corollary 16 Let $(X, p)$ be a complete partial metric space and let $f: X \rightarrow X$ be a mapping such that there exists $\bar{\alpha}: X \times X \rightarrow[0,1[$ with

$$
\theta(a, b)=\sup \{\bar{\alpha}(x, y): a \leq p(x, y) \leq b\}<1
$$

for every $0 \leq a \leq b$, and such that

$$
p(f(x), f(y)) \leq \frac{\bar{\alpha}}{2}(x, y)\left(p(x, y)+\frac{1}{2}[p(x, f(x))+p(y, f(y))]\right)
$$

for all $x, y \in X$. Then $f$ has a unique fixed point $x^{*} \in X$ and the Picard sequence of iterates $\left\{f^{n}(x)\right\}_{n \in \mathbb{N}}$ converges with respect to $\tau\left(p^{s}\right)$, for every $x \in X$, to $x^{*}$. Moreover, $p\left(x^{*}, x^{*}\right)=0$.

As a consequence of Theorem 15, we obtain the announced partial metric versions of Theorems 9 and 10.

Corollary 17 Let $(X, p)$ be a complete partial metric space and let $f: X \rightarrow X$ be a weakly contractive mapping. Then $f$ has a unique fixed point $x^{*} \in X$ and the Picard sequence of iterates $\left\{f^{n}(x)\right\}_{n \in \mathbb{N}}$ converges with respect to $\tau\left(p^{s}\right)$, for every $x \in X$, to $x^{*}$. Moreover, $p\left(x^{*}, x^{*}\right)=0$. 
Corollary 18 Let $(X, p)$ be a complete partial metric space and let $f: X \rightarrow X$ be a weakly Kannan mapping. Then $f$ has a unique fixed point $x \in X$ and the Picard sequence of iterates $\left\{f^{n}(x)\right\}_{n \in \mathbb{N}}$ converges with respect to $\tau\left(p^{s}\right)$, for every $x \in X$, to $x^{*}$. Moreover, $p\left(x^{*}, x^{*}\right)=0$.

It is clear that Theorems 9 and 10 follow as special cases of Corollaries 17 and 18, respectively, when the partial metric is a metric.

We end this subsection by stressing, on the one hand, that in all above results, we have proved that the Picard sequences of iterates are convergent to the fixed point with respect to $\tau\left(p^{s}\right)$, and thus we immediately conclude that such a convergence is also with respect to $\tau(p)$. On the other hand, it is clear that when, in the statements of the aforementioned results, we replace the partial metric by a metric, we retrieve the classical fixed points results for weakly contractive mappings, Theorem 9, and for weakly Kannan mappings, Theorem 10.

\subsection{Weakly contractive and weakly Kannan mappings in complete partial metric spaces: the cyclical case}

In this section, we present the extensions of Corollaries 17 and 18 to the cyclical case, i.e., when we consider a cyclical representation of a complete partial metric space and either weakly cyclic contractive mappings or weakly cyclic Kannan mappings.

Inspired, in part, by Theorem 3 (and other results given in [2]), Rus introduced the notion of a cyclic representation in [46] (see also [47] and [48]). According to Definition 2.1 in [46], given a nonempty set $X$ and a mapping $f: X \rightarrow X$, a collection $A_{1}, \ldots, A_{m}$ of nonempty subsets of $X(m \in \mathbb{N})$ is said to be a cyclic representation of $X$ with respect to $f$ provided that the following conditions are satisfied:

(1) $X=\bigcup_{i=1}^{m} A_{i}$;

(2) $f\left(A_{i}\right) \subseteq A_{i+1}$ for all $1 \leq i \leq m$, where $A_{m+1}=A_{1}$.

From now on, for our subsequent work convenience, given a topological space $(X, \tau)$, a nonempty subset $Y \subseteq X$ and $f: Y \rightarrow Y$, we will say that a collection $A_{1}, \ldots, A_{m}$ of nonempty subsets of $X(m \in \mathbb{N})$ is a closed cyclic representation of $Y$ with respect to $f$ and $\tau$ provided that the following conditions are satisfied:

(1) $A_{1}, \ldots, A_{m}$ is a cyclic representation of $Y$ with respect to $f$;

(2) $A_{i}$ is closed with respect to $\tau$ for all $1 \leq i \leq m$.

In the sequel, given a topological space $(X, \tau)$ and a nonempty subset $Y \subseteq X$ which is closed with respect to $\tau$, we will say, for short, that $Y$ is a $\tau$-closed subset of $X$. Thus, a collection $A_{1}, \ldots, A_{m}$ of nonempty subsets of $X(m \in \mathbb{N})$ will be called a $\tau$-closed cyclic representation of $Y$ with respect to $f$ provided that $A_{1}, \ldots, A_{m}$ is a closed cyclic representation of $Y$ with respect to $f$ and $\tau$.

Notice that if $(X, p)$ is a partial metric space and $Y \subseteq X$ is $\tau(p)$-closed, then $Y$ is $\tau\left(p^{s}\right)$ closed. Hence, if $(X, p)$ is a complete partial metric space and $Y \subseteq X$, then $(Y, p)$ is a complete partial metric space provided that $Y$ is $\tau(p)$-closed.

Next, we extend the notions of a weakly contractive mapping and a weakly Kannan mapping to the cyclical context in the spirit of Definition 1.3 in [47].

Definition 19 Let $(X, p)$ be a complete partial metric space and $A_{1}, \ldots, A_{m}(m \in \mathbb{N})$ be a collection of nonempty subsets of $X$. A mapping $f: Y \rightarrow Y$ is called a weakly cyclic contractive mapping if the following conditions are satisfied: 
(1) $A_{1}, \ldots, A_{m}$ is a $\tau(p)$-cyclic representation of $Y$ with respect to $f$,

(2) there exists $\bar{\alpha}: Y \times Y \rightarrow[0,1[$ such that for every $0 \leq a \leq b$

$$
\theta(a, b)=\sup \{\bar{\alpha}(x, y): a \leq p(x, y) \leq b\}<1,
$$

and for any $x \in A_{i}, y \in A_{i+1}$

$$
p(f(x), f(y)) \leq \bar{\alpha}(x, y) p(x, y) .
$$

Definition 20 Let $(X, p)$ be a complete partial metric space and $A_{1}, \ldots, A_{m}(m \in \mathbb{N})$ be a collection of nonempty subsets of $X$. A mapping $f: Y \rightarrow Y$ is called a weakly cyclic Kannan mapping if the following conditions are satisfied:

(1) $A_{1}, \ldots, A_{m}$ is a $\tau(p)$-cyclic representation of $Y$ with respect to $f$,

(2) there exists $\bar{\alpha}: Y \times Y \rightarrow[0,1[$ such that for every $0 \leq a \leq b$

$$
\theta(a, b)=\sup \{\bar{\alpha}(x, y): a \leq p(x, y) \leq b\}<1,
$$

and for any $x \in A_{i}, y \in A_{i+1}$

$$
p(f(x), f(y)) \leq \frac{\bar{\alpha}(x, y)}{2}[p(x, f(x))+p(y, f(y))]
$$

When we consider the partial metric as a metric in Definition 20, we retrieve as a particular case the well-known notion of cyclic Kannan mappings in metric spaces, i.e., the mapping satisfying the contractive condition in Theorem 4 in Section 1 . In addition, notice that when the partial metric is in fact a metric, the preceding notion of a weakly Kannan mapping differs from the one for metric spaces given by Petric in [49].

We prove the following result with the aim of extending the aforesaid corollaries to the new context.

Theorem 21 Let $(X, p)$ be a complete partial metric space and $A_{1}, \ldots, A_{m}(m \in \mathbb{N})$ be a collection of nonempty subsets of $X$ and $Y \subseteq X$. Let $f: Y \rightarrow Y$ be a mapping such that:

(1) $A_{1}, \ldots, A_{m}$ is a $\tau(p)$-cyclic representation of $Y$ with respect to $f$,

(2) there exists $\bar{\alpha}: Y \times Y \rightarrow[0,1[$ with

$$
\theta(a, b)=\sup \{\bar{\alpha}(x, y): a \leq p(x, y) \leq b\}<1
$$

such that for every $0 \leq a \leq b$, and such that

$$
p(f(x), f(y)) \leq \bar{\alpha}(x, y) \max \left\{p(x, y), \frac{1}{2}[p(x, f(x))+p(y, f(y))]\right\}
$$

for any $x \in A_{i}, y \in A_{i+1}$.

Then $f$ has a unique fixed point $x^{*} \in \bigcap_{i=1}^{m} A_{i}$ and the Picard sequence of iterates $\left\{f^{n}(x)\right\}_{n \in \mathbb{N}}$ converges with respect to $\tau\left(p^{s}\right)$, for every $x \in Y$, to $x^{*}$. Moreover, $p\left(x^{*}, x^{*}\right)=0$. 
Proof Let $x_{0} \in Y=\bigcup_{i=1}^{m} A_{i}$, and set

$$
x_{n}=f\left(x_{n-1}\right)=f^{n}\left(x_{0}\right) \quad(n \in \mathbb{N}) .
$$

For any $n \in \mathbb{N}$, there is $i_{n} \in\{i, \ldots, m\}$ such that $x_{n} \in A_{i_{n}}$ and $x_{n+1} \in A_{i_{n}+1}$. Then by (2.6), we have

$$
\begin{aligned}
p\left(x_{n}, x_{n+1}\right) & =p\left(f\left(x_{n-1}\right), f\left(x_{n}\right)\right) \\
& \leq \bar{\alpha}\left(x_{n-1}, x_{n}\right) M\left(x_{n-1}, x_{n}\right),
\end{aligned}
$$

where $M\left(x_{n-1}, x_{n}\right)$ is given as in the proof of Theorem 15 . Now, following exactly the same arguments as those given in the proof of Theorem 15, we obtain the following facts:

(1) For all $n \in \mathbb{N}$,

$$
p\left(x_{n}, x_{n+1}\right) \leq \bar{\alpha}\left(x_{n-1}, x_{n}\right) p\left(x_{n-1}, x_{n}\right)
$$

and thus the sequence $\left\{p\left(x_{n}, x_{n+1}\right)\right\}_{n \in \mathbb{N}}$ is nonincreasing converging to $p=\inf \left\{p\left(x_{n-1}, x_{n}\right): n \in \mathbb{N}\right\}$.

(2)

$$
\lim _{n \rightarrow \infty} p^{s}\left(x_{n}, x_{n+1}\right)=\lim _{n \rightarrow \infty} p\left(x_{n}, x_{n+1}\right)=\lim _{n \rightarrow \infty} p\left(x_{n}, x_{n}\right)=p=0 .
$$

(3) For all $k \in \mathbb{N}$,

$$
p^{s}\left(x_{n}, x_{n+k}\right) \leq 2 \frac{\theta^{n}}{1-\theta} p\left(x_{0}, x_{1}\right)
$$

where $\theta=\theta\left(0, p\left(x_{0}, x_{1}\right)\right)$.

The inequality given in assertion (3) guarantees that the sequence $\left\{x_{n}\right\}_{n \in \mathbb{N}}$ is Cauchy in the metric subspace $\left(Y, p^{s}\right)$. Since $Y$ is $\tau(p)$-closed, the subspace $\left(Y, p^{s}\right)$ is complete. So, the sequence $\left\{x_{n}\right\}_{n \in \mathbb{N}}$ is convergent in $\left(Y, p^{s}\right)$ to any $y^{*} \in Y$. Whence we have that

$$
\lim _{n \rightarrow \infty} p^{s}\left(x_{n}, y^{*}\right)=0 \text {. }
$$

It follows that

$$
p\left(y^{*}, y^{*}\right)=\lim _{n \rightarrow \infty} p\left(x_{n}, y^{*}\right)=\lim _{n, m \rightarrow \infty} p\left(x_{n}, x_{m}\right) .
$$

Since $\left\{x_{n}\right\}_{n \in \mathbb{N}}$ is a Cauchy sequence in $\left(Y, p^{s}\right)$, we obtain that

$$
\lim _{n, m \rightarrow \infty} p^{s}\left(x_{n}, x_{m}\right)=0
$$

Thus, from the equality in the above assertion (2), we have $\lim _{n \rightarrow \infty} p\left(x_{n}, x_{n}\right)=0$, and then from the definition of $p^{s}$, we have $\lim _{n, m \rightarrow \infty} p\left(x_{n}, x_{m}\right)=0$. Therefore, from (2.7), we deduce 
that

$$
p\left(y^{*}, y^{*}\right)=\lim _{n \rightarrow \infty} p\left(x_{n}, y^{*}\right)=\lim _{n, m \rightarrow \infty} p\left(x_{n}, x_{m}\right)=0
$$

This shows that the Picard sequence of iterates $\left\{x_{n}\right\}_{n \in \mathbb{N}}$ converges to a point $y^{*} \in Y$ with respect to $\tau\left(p^{s}\right)$ such that $p\left(y^{*}, y^{*}\right)=0$.

Next, we show that $y^{*} \in \bigcap_{i=1}^{m} A_{i}$.

It is clear that the sequence $\left\{x_{n}\right\}_{n \in \mathbb{N}}$ has an infinite number of terms in each $A_{i}, i=$ $1, \ldots, m$. Since $\left\{x_{n}\right\}_{n \in \mathbb{N}}$ converges to $y^{*}$ in $\left(Y, p^{s}\right)$, we can construct in each $A_{i}, i=1, \ldots, m$, a subsequence of $\left\{x_{n}\right\}_{n \in \mathbb{N}}$ which converges to $y^{*}$. Moreover, the fact that each $A_{i}, i=1, \ldots, m$, is $\tau\left(p^{s}\right)$-closed yields that $y^{*} \in A_{i}$ for all $i=1, \ldots, m$. Thus,

$$
y^{*} \in \bigcap_{i=1}^{m} A_{i} .
$$

Then $\bigcap_{i=1}^{m} A_{i} \neq \emptyset$, and we can consider the restriction of the mapping $f$ to $\bigcap_{i=1}^{m} A_{i}$,

$$
\left.f\right|_{\bigcap_{i=1}^{m} A_{i}}: \bigcap_{i=1}^{m} A_{i} \rightarrow \bigcap_{i=1}^{m} A_{i}
$$

which satisfies the conditions of Theorem 15 as $\left(\bigcap_{i=1}^{m} A_{i}, p\right)$ is also complete because $\bigcap_{i=1}^{m} A_{i}$ is $\tau\left(p^{s}\right)$-closed and $\left(Y, p^{s}\right)$ is complete. According to the aforementioned result, $\left.f\right|_{\bigcap_{i=1}^{m} A_{i}}$ has a unique fixed point $x^{*} \in \bigcap_{i=1}^{m} A_{i}$ such that $p\left(x^{*}, x^{*}\right)=0$.

Next, we claim that for any initial value $y_{0} \in Y$, the Picard sequence of iterates $\left\{f^{n}\left(y_{0}\right)\right\}_{n \in \mathbb{N}}$ has the same limit point $x^{*} \in \bigcap_{i=1}^{m} A_{i}$. Indeed, let $y_{0} \in Y=\bigcup_{i=1}^{m} A_{i}$. Then the same arguments as those applied to the Picard sequence of iterates $\left\{f^{n}\left(x_{0}\right)\right\}_{n \in \mathbb{N}}$ run to show that $\lim _{n \rightarrow \infty} p\left(f^{n}\left(y_{0}\right), f^{n}\left(y_{0}\right)\right)=0$. Moreover, there exists $i_{0} \in\{1, \ldots, m\}$ such that $y_{0} \in A_{i_{0}}$. Since $x^{*} \in \bigcap_{i=1}^{m} A_{i}$, it follows that $x^{*} \in A_{i_{0}+1}$. We obtain from (2.6) that

$$
p\left(f\left(y_{0}\right), f\left(x^{*}\right)\right) \leq \bar{\alpha}\left(y_{0}, x^{*}\right) M\left(y_{0}, x^{*}\right)
$$

where

$$
\begin{aligned}
M\left(y_{0}, x^{*}\right) & =\max \left\{p\left(y_{0}, x^{*}\right), \frac{1}{2}\left[p\left(y_{0}, f\left(y_{0}\right)\right)+p\left(x^{*}, f\left(x^{*}\right)\right)\right]\right\} \\
& =\max \left\{p\left(y_{0}, x^{*}\right), \frac{1}{2} p\left(y_{0}, f\left(y_{0}\right)\right)\right\} .
\end{aligned}
$$

Now, we show that the following inequality holds:

$$
p\left(f\left(y_{0}\right), f\left(x^{*}\right)\right) \leq \bar{\alpha}\left(y_{0}, x^{*}\right) p\left(y_{0}, x^{*}\right)
$$

We consider the following two cases with this aim:

Case 1. If $M\left(y_{0}, x^{*}\right)=p\left(y_{0}, x^{*}\right)$, then

$$
p\left(f\left(y_{0}\right), f\left(x^{*}\right)\right) \leq \bar{\alpha}\left(y_{0}, x^{*}\right) p\left(y_{0}, x^{*}\right) .
$$


Case 2. If $M\left(y_{0}, x^{*}\right)=\frac{1}{2} p\left(y_{0}, f\left(y_{0}\right)\right)$, then

$$
\begin{aligned}
p\left(f\left(y_{0}\right), f\left(x^{*}\right)\right) & \leq \frac{\bar{\alpha}\left(y_{0}, x^{*}\right)}{2} p\left(y_{0}, f\left(y_{0}\right)\right) \\
& \leq \frac{\bar{\alpha}\left(y_{0}, x^{*}\right)}{2}\left[p\left(y_{0}, x^{*}\right)+p\left(x^{*}, f\left(y_{0}\right)\right)\right],
\end{aligned}
$$

i.e.,

$$
\begin{aligned}
p\left(f\left(y_{0}\right), f\left(x^{*}\right)\right) & \leq \frac{\bar{\alpha}\left(y_{0}, x^{*}\right)}{2-\bar{\alpha}\left(y_{0}, x^{*}\right)} p\left(y_{0}, x^{*}\right) \\
& \leq \bar{\alpha}\left(y_{0}, x^{*}\right) p\left(y_{0}, x^{*}\right) .
\end{aligned}
$$

Therefore, in any case,

$$
p\left(f\left(y_{0}\right), f\left(x^{*}\right)\right) \leq \bar{\alpha}\left(y_{0}, x^{*}\right) p\left(y_{0}, x^{*}\right) .
$$

Suppose that $y_{0} \neq x^{*}$ because otherwise we get the desired conclusion. Then $r_{1}=p\left(y_{0}, x^{*}\right)>$ 0 , and hence

$$
\bar{\alpha}\left(y_{0}, x^{*}\right) \leq \theta\left(\frac{r_{1}}{2}, r_{1}\right)<1
$$

It follows that

$$
p\left(f\left(y_{0}\right), f\left(x^{*}\right)\right) \leq \theta\left(\frac{r_{1}}{2}, r_{1}\right) p\left(y_{0}, x^{*}\right) .
$$

Moreover, it is easily seen that

$$
p\left(f^{n}\left(y_{0}\right), x^{*}\right) \leq \bar{\alpha}\left(f^{n-1}\left(y_{0}\right), x^{*}\right) p\left(f^{n-1}\left(y_{0}\right), x^{*}\right)
$$

for all $n \in \mathbb{N}$. Since $\bar{\alpha}\left(f^{n-1}\left(y_{0}\right), x^{*}\right) \leq 1$, we obtain that

$$
p\left(f^{n}\left(y_{0}\right), x^{*}\right) \leq p\left(f^{n-1}\left(y_{0}\right), x^{*}\right)
$$

for all $n \in \mathbb{N}$. It follows that the sequence $\left\{p\left(f^{n}\left(y_{0}\right), x^{*}\right)\right\}_{n \in \mathbb{N}}$ is nonincreasing, and then it is convergent to a real number

$$
p=\inf \left\{p\left(f^{n}\left(y_{0}\right), x^{*}\right): n \in \mathbb{N}\right\} .
$$

For the purpose of contradiction, assume that $p>0$. Then for all $n \in \mathbb{N}$, we have

$$
0<p \leq p\left(f^{n}\left(y_{0}\right), x^{*}\right) \leq p\left(f^{n-1}\left(y_{0}\right), x^{*}\right) \leq \cdots \leq p\left(y_{0}, x^{*}\right),
$$

and from the definition of $\theta=\theta\left(p, p\left(y_{0}, x^{*}\right)\right)$, we obtain that $\bar{\alpha}\left(f^{n}\left(y_{0}\right), x^{*}\right) \leq \theta$ for all $n \in \mathbb{N}$. Thus,

$$
p \leq p\left(f^{n}\left(y_{0}\right), x^{*}\right) \leq \bar{\alpha}\left(f^{n}\left(y_{0}\right), x^{*}\right) p\left(f^{n-1}\left(y_{0}\right), x^{*}\right) \leq \theta^{n} p\left(y_{0}, x^{*}\right)
$$


for all $n \in \mathbb{N}$. Whence we obtain a contradiction, since $0 \leq \theta<1$, and hence $\lim _{n \rightarrow \infty} \theta^{n}=0$. Therefore, $p=0$ and $\lim _{n \rightarrow \infty} p\left(f^{n}\left(y_{0}\right), x^{*}\right)=0$.

Taking into account that $\lim _{n \rightarrow \infty} p\left(f^{n}\left(y_{0}\right), f^{n}\left(y_{0}\right)\right)=0$, we deduce that

$$
\lim _{n \rightarrow \infty} p^{s}\left(f^{n}\left(y_{0}\right), x^{*}\right)=0
$$

Thus, the Picard iteration converges, with respect to $\tau\left(p^{s}\right)$, to $x^{*}$ for any initial point $y_{0} \in Y$.

Finally, we prove the uniqueness of a fixed point. Assume that there exists $y^{*} \in Y$ such that $f\left(y^{*}\right)=y^{*}$ and $y^{*} \neq x^{*}$. Then $r_{2}=p\left(x^{*}, y^{*}\right)>0$, and thus

$$
\bar{\alpha}\left(x^{*}, y^{*}\right) \leq \theta\left(\frac{r_{2}}{2}, r_{2}\right)<1
$$

Moreover, there exists $i_{0} \in\{1, \ldots, m\}$ such that $y^{*} \in A_{i_{0}}$. Since $x^{*} \in \bigcap_{i=1}^{m} A_{i}$ we have that $x^{*} \in A_{i_{0}+1}$. Then from (2.6) and the fact that

$$
p\left(x^{*}, x^{*}\right)<p\left(x^{*}, y^{*}\right) \text { and } p\left(y^{*}, y^{*}\right) \leq p\left(x^{*}, y^{*}\right),
$$

we have that

$$
\begin{aligned}
p\left(x^{*}, y^{*}\right) & =p\left(f\left(x^{*}\right), f\left(y^{*}\right)\right) \\
& \leq \bar{\alpha}\left(x^{*}, y^{*}\right) M\left(x^{*}, y^{*}\right) \\
& =\bar{\alpha}\left(x^{*}, y^{*}\right) \max \left\{p\left(x^{*}, y^{*}\right), \frac{1}{2}\left[p\left(x^{*}, x^{*}\right)+p\left(y^{*}, y^{*}\right)\right]\right\} \\
& =\bar{\alpha}\left(x^{*}, y^{*}\right) p\left(x^{*}, y^{*}\right) \\
& \leq \theta\left(\frac{r_{2}}{2}, r_{2}\right) p\left(x^{*}, y^{*}\right),
\end{aligned}
$$

which is a contradiction. Thus, $x^{*}$ is the unique fixed point of $f$. This concludes the proof.

Theorem 21 yields as a particular case the following result.

Corollary 22 Let $(X, p)$ be a complete partial metric space and $A_{1}, \ldots, A_{m}(m \in \mathbb{N})$ be a collection of nonempty subsets of $X$ and $Y \subseteq X$. Let $f: Y \rightarrow Y$ be a mapping such that:

(1) $A_{1}, \ldots, A_{m}$ is a $\tau(p)$-cyclic representation of $Y$ with respect to $f$,

(2) there exists $\bar{\alpha}: Y \times Y \rightarrow[0,1[$ with

$$
\theta(a, b)=\sup \{\bar{\alpha}(x, y): a \leq p(x, y) \leq b\}<1
$$

such that for every $0 \leq a \leq b$, and such that

$$
p(f(x), f(y)) \leq \frac{\bar{\alpha}}{2}(x, y)\left(p(x, y)+\frac{1}{2}[p(x, f(x))+p(y, f(y))]\right)
$$

for any $x \in A_{i}, y \in A_{i+1}$. 
Then $f$ has a fixed point $x^{*} \in \bigcap_{i=1}^{m} A_{i}$ and the Picard sequence of iterates $\left\{f^{n}(x)\right\}_{n \in \mathbb{N}}$ converges with respect to $\tau\left(p^{s}\right)$, for every $x \in Y$, to $x^{*}$. Moreover, $p\left(x^{*}, x^{*}\right)=0$.

As a consequence of Theorem 21, we obtain the following fixed point results which extend Corollaries 17 and 18 to the cyclic case.

Corollary 23 Let $(X, p)$ be a complete partial metric space and $A_{1}, \ldots, A_{m}(m \in \mathbb{N})$ be a collection of nonempty subsets of $X$ and $Y \subseteq X$. Suppose that $f: Y \rightarrow Y$ is a weakly cyclic contractive mapping. Then $f$ has a unique fixed point $x^{*} \in \bigcap_{i=1}^{m} A_{i}$ and the Picard sequence of iterates $\left\{f^{n}(x)\right\}_{n \in \mathbb{N}}$ converges with respect to $\tau\left(p^{s}\right)$, for every $x \in Y$, to $x^{*}$. Moreover, $p\left(x^{*}, x^{*}\right)=0$.

Corollary 24 Let $(X, p)$ be a complete partial metric space and $A_{1}, \ldots, A_{m}(m \in \mathbb{N})$ be a collection of nonempty subsets of $X$ and $Y \subseteq X$. Suppose that $f: Y \rightarrow Y$ is a weakly cyclic Kannan mapping. Then $f$ has a unique fixed point $x^{*} \in \bigcap_{i=1}^{m} A_{i}$ and the Picard sequence of iterates $\left\{f^{n}(x)\right\}_{n \in \mathbb{N}}$ converges with respect to $\tau\left(p^{s}\right)$, for every $x \in Y$, to $x^{*}$. Moreover, $p\left(x^{*}, x^{*}\right)=0$.

As in the case of the results given in Section 2.1, we want to remark that in all above results, we have obtained that the Picard sequences of iterates are convergent to the fixed point with respect to $\tau\left(p^{s}\right)$, and thus the convergence is also with respect to $\tau(p)$.

Note that if we replace the partial metric by a metric in the statements of Corollaries 23 and 24, we obtain the following metric fixed point results, the publication of which in the literature so far we are not aware of.

Corollary 25 Let $(X, d)$ be a complete metric space and $A_{1}, \ldots, A_{m}(m \in \mathbb{N})$ be a collection of nonempty subsets of $X$ and $Y \subseteq X$. Suppose that $f: Y \rightarrow Y$ is a weakly cyclic contractive mapping. Then $f$ has a unique fixed point $x^{*} \in \bigcap_{i=1}^{m} A_{i}$ and the Picard sequence of iterates $\left\{f^{n}(x)\right\}_{n \in \mathbb{N}}$ converges with respect to $\tau(d)$, for every $x \in Y$, to $x^{*}$.

Corollary 26 Let $(X, d)$ be a complete metric space and $A_{1}, \ldots, A_{m}(m \in \mathbb{N})$ be a collection of nonempty subsets of $X$ and $Y \subseteq X$. Suppose that $f: Y \rightarrow Y$ is a weakly cyclic Kannan mapping. Then $f$ has a unique fixed point $x^{*} \in \bigcap_{i=1}^{m} A_{i}$ and the Picard sequence of iterates $\left\{f^{n}(x)\right\}_{n \in \mathbb{N}}$ converges with respect to $\tau(d)$, for every $x \in Y$, to $x^{*}$.

Furthermore, from Corollary 26, we obtain exactly the fixed point for Kannan mappings given in [4], i.e., Theorem 4 in Section 1.

Corollary 27 Let $(X, d)$ be a complete metric space and $A_{1}, \ldots, A_{m}(m \in \mathbb{N})$ be a collection of nonempty subsets of $X$ and $Y \subseteq X$. Suppose that $f: Y \rightarrow Y$ is a cyclic Kannan mapping. Then $f$ has a unique fixed point $x^{*} \in \bigcap_{i=1}^{m} A_{i}$ and the Picard sequence of iterates $\left\{f^{n}(x)\right\}_{n \in \mathbb{N}}$ converges with respect to $\tau(d)$, for every $x \in Y$, to $x^{*}$.

\subsection{Weakly contractive and weakly Kannan mappings in complete partial metric spaces: a Picard operator perspective}

According to [39], given a partial metric space $(X, p)$, a mapping $f: X \rightarrow X$ is a Picard operator provided that $f$ has a unique fixed point and that the Picard sequence of iterates $\left\{f^{n}(x)\right\}_{n \in \mathbb{N}}$ is convergent, for every $x \in X$, to the fixed point with respect to $\tau\left(p^{s}\right)$. 
In the light of the theory exposed in Sections 2.1 and 2.2, in particular as a consequence of Theorem 15 and Theorem 21, every weakly contractive mapping and every weakly Kannan mapping defined in partial metric spaces are Picard operators in the sense of [39]. However, in partial metric spaces, we can relax the preceding notion as follows.

Definition 28 Let $(X, p)$ be a partial metric. We will say that a mapping $f: X \rightarrow X$ is a Picard operator with respect to $p$ (or $p$-Picard operator for short) provided that $f$ has a unique fixed point and that the Picard sequence of iterates $\left\{f^{n}(x)\right\}_{n \in \mathbb{N}}$ is convergent, for every $x \in X$, to the fixed point with respect to $\tau(p)$.

Of course, Theorem 15 and Theorem 21 guarantee that every weakly contractive mapping and every weakly Kannan mapping defined in partial metric spaces are examples of $p$-Picard operators. It follows that every mapping satisfying the original contractive condition of Matthews given in Theorem 6 is also a $p$-Picard operator.

Following [39], given a partial metric space $(X, p)$ and a $p$-Picard operator $f: X \rightarrow X$ with fixed point $x^{*} \in X$, we will say that the fixed point problem for such a mapping is well posed with respect to $p$ whenever the following property holds:

If $\left\{x_{n}\right\}_{n \in \mathbb{N}}$ is a sequence in $X$ such that $\lim _{n \rightarrow \infty} p\left(x_{n}, f\left(x_{n}\right)\right)=0$, then $\left\{x_{n}\right\}_{n \in \mathbb{N}}$ converges to $x^{*}$ with respect to $\tau(p)$.

The next result yields the well-posedness of the fixed point problem for weakly (cyclic) contractive mappings and for weakly (cyclic) Kannan mappings in our sense.

Theorem 29 Let $(X, p)$ be a complete partial metric space and let $f: X \rightarrow X$ be a mapping satisfying all the requirements in the statement of Theorem 15 , then the fixed point problem for $f$ is well posed with respect to $p$ if and only if for every sequence $\left\{x_{n}\right\}_{n \in \mathbb{N}}$ in $X$ such that $\lim _{n \rightarrow \infty} p\left(x_{n}, f\left(x_{n}\right)\right)=0$, there exists a subsequence $\left\{x_{n_{k}}\right\}_{k \in \mathbb{N}}$ with $\lim _{k \rightarrow \infty} \bar{\alpha}\left(x_{n_{k}}, x^{*}\right)<1$, where $x^{*}$ is the unique fixed point of $f$.

Proof First of all, we prove that the following inequality holds for all $x \in X$ with $x \neq x^{*}$ :

$$
p\left(x, x^{*}\right) \leq \frac{1}{1-\bar{\alpha}\left(x, x^{*}\right)} p(x, f(x))
$$

where $x^{*}$ is the fixed point of $f$ provided by Theorem 15 .

Since $p\left(x^{*}, f\left(x^{*}\right)\right)=0$, we have

$$
\max \left\{p\left(x, x^{*}\right), \frac{1}{2}\left[p(x, f(x))+p\left(x^{*}, f\left(x^{*}\right)\right)\right]\right\}=\max \left\{p\left(x, x^{*}\right), \frac{1}{2} p(x, f(x))\right\},
$$

for all $x \in X$.

Next, we distinguish two cases:

Case 1. Suppose that $x \in X$ with $x \neq x^{*}$ such that $\max \left\{p\left(x, x^{*}\right), \frac{1}{2} p(x, f(x))\right\}=p\left(x, x^{*}\right)$. Then

$$
\begin{aligned}
p\left(x, x^{*}\right) & \leq p(x, f(x))+p\left(f(x), f\left(x^{*}\right)\right) \\
& \leq p(x, f(x))+\bar{\alpha}\left(x, x^{*}\right) p\left(x, x^{*}\right) .
\end{aligned}
$$

It follows that

$$
p\left(x, x^{*}\right) \leq \frac{1}{1-\bar{\alpha}\left(x, x^{*}\right)} p(x, f(x)) .
$$


Case 2. Suppose that $x \in X$ with $x \neq x^{*}$ such that $\max \left\{p\left(x, x^{*}\right), \frac{1}{2} p(x, f(x))\right\}=\frac{1}{2} p(x, f(x))$.

Then

$$
\begin{aligned}
p\left(x, x^{*}\right) & \leq p(x, f(x))+p\left(f(x), f\left(x^{*}\right)\right) \\
& \leq p(x, f(x))+\bar{\alpha}\left(x, x^{*}\right) \frac{1}{2} p(x, f(x)) \\
& =\left(1+\frac{\bar{\alpha}\left(x, x^{*}\right)}{2}\right) p(x, f(x)) .
\end{aligned}
$$

Since

$$
1+\frac{\bar{\alpha}\left(x, x^{*}\right)}{2} \leq \frac{1}{1-\bar{\alpha}\left(x, x^{*}\right)}
$$

we obtain that

$$
p\left(x, x^{*}\right) \leq \frac{1}{1-\bar{\alpha}\left(x, x^{*}\right)} p(x, f(x)) .
$$

So, we have shown that inequality (2.8) holds for all $x \in X$ with $x \neq x^{*}$.

Now, we assume that the fixed point problem is well posed and consider a sequence $\left\{x_{n}\right\}_{n \in \mathbb{N}}$ in $X$ such that $\lim _{n \rightarrow \infty} p\left(x_{n}, f\left(x_{n}\right)\right)=0$. Then it is clear that there exists a subsequence $\left\{x_{n_{k}}\right\}_{k \in \mathbb{N}}$ of $\left\{x_{n}\right\}_{n \in \mathbb{N}}$ such that $\lim _{k \rightarrow \infty} \bar{\alpha}\left(x_{n_{k}}, x^{*}\right)=L$ with $0 \leq L \leq 1$ (observe that the sequence $\left\{\bar{\alpha}\left(x_{n_{k}}, x^{*}\right)\right\}_{k \in \mathbb{N}} \subseteq[0,1[)$. Next, we prove that $L<1$. To this end, suppose that $L=1$.

Since the fixed problem is well posed, we have that $\lim _{n \rightarrow \infty} p\left(x_{n}, x^{*}\right)=0$. Then there exists $k_{0} \in \mathbb{N}$ such that $p\left(x_{n_{k}}, x^{*}\right)<1$ and

$$
1<\bar{\alpha}\left(x_{n_{k}}, x^{*}\right)+1-\theta(0,1)
$$

for all $k \geq k_{0}$. It follows that $\theta(0,1)<\bar{\alpha}\left(x_{n_{k}}, x^{*}\right) \leq \theta(0,1)$ which is a contradiction. We conclude that $\lim _{k \rightarrow \infty} \bar{\alpha}\left(x_{n_{k}}, x^{*}\right)<1$.

Next, assume that given a sequence $\left\{x_{n}\right\}_{n \in \mathbb{N}}$ in $X$ with $\lim _{n \rightarrow \infty} p\left(x_{n}, f\left(x_{n}\right)\right)=0$, we will show the well-posedness of the fixed point problem. To this end, consider, for the propose of contradiction, that the sequence $\left\{p\left(x_{n}, x^{*}\right)-p\left(x^{*}, x^{*}\right)\right\}_{n \in \mathbb{N}}$ does not converge to 0 . Then there exists $M>0$ and a subsequence $\left\{x_{n_{k}}\right\}_{k \in \mathbb{N}}$ of $\left\{x_{n}\right\}_{n \in \mathbb{N}}$ such that

$$
M \leq p\left(x_{n_{k}}, x^{*}\right)-p\left(x^{*}, x^{*}\right)
$$

for all $k \in \mathbb{N}$.

By (2.8), we have that

$$
p\left(x_{n_{k}}, x^{*}\right)-p\left(x^{*}, x^{*}\right) \leq \frac{1}{1-\bar{\alpha}\left(x_{n_{k}}, x^{*}\right)} p\left(x_{n_{k}}, f\left(x_{n_{k}}\right)\right)
$$

for all $k \in \mathbb{N}$. Since $\lim _{k \rightarrow \infty} p\left(x_{n_{k}}, f\left(x_{n_{k}}\right)\right)=0$, we have guaranteed by the hypothesis the existence of a subsequence $\left\{x_{n_{k_{m}}}\right\}_{m \in \mathbb{N}}$ of $\left\{x_{n_{k}}\right\}_{k \in \mathbb{N}}$ such that $\lim _{m \rightarrow \infty} \bar{\alpha}\left(x_{n_{k_{m}}}, x^{*}\right)<1$. 
Thus, we obtain that

$$
0<M \leq \frac{1}{1-\lim _{m \rightarrow \infty} \bar{\alpha}\left(x_{n_{k_{m}}}, x^{*}\right)} \lim _{m \rightarrow \infty} p\left(x_{n_{k_{m}}}, f\left(x_{n_{k_{m}}}\right)\right)=0,
$$

which is impossible. So, $\lim _{n \rightarrow \infty} p\left(x_{n}, x^{*}\right)-p\left(x^{*}, x^{*}\right)=0$, and thus the sequence $\left\{x_{n}\right\}_{n \in \mathbb{N}}$ is convergent to $x^{*}$ with respect to $\tau(p)$. Therefore, the fixed point problem is well posed.

Notice that the well-posedness yielded by Theorem 29 is in fact with respect to $p^{s}$ since

$$
p\left(x_{n}, x^{*}\right)-p\left(x_{n}, x_{n}\right) \leq p\left(x_{n}, x^{*}\right)
$$

for all $n \in \mathbb{N}$ and $\lim _{n \rightarrow \infty} p\left(x_{n}, x^{*}\right)=0$.

Corollary 30 Let $(X, p)$ be a complete partial metric space and let $f: X \rightarrow X$ be a weakly contractive mapping. Then the fixed point problem for $f$ is well posed with respect to $p$ if and only if for every sequence $\left\{x_{n}\right\}_{n \in \mathbb{N}}$ in $X$ such that $\lim _{n \rightarrow \infty} p\left(x_{n}, f\left(x_{n}\right)\right)=0$, there exists a subsequence $\left\{x_{n_{k}}\right\}_{k \in \mathbb{N}}$ with $\lim _{k \rightarrow \infty} \bar{\alpha}\left(x_{n_{k}}, x^{*}\right)<1$, where $x^{*}$ is the unique fixed point off.

Corollary 31 Let $(X, d)$ be a complete metric space and let $f: X \rightarrow X$ be a weakly contractive mapping. Then the fixed point problem for $f$ is well posed with respect to $d$ if and only if for every sequence $\left\{x_{n}\right\}_{n \in \mathbb{N}}$ in $X$ such that $\lim _{n \rightarrow \infty} d\left(x_{n}, f\left(x_{n}\right)\right)=0$, there exists a subsequence $\left\{x_{n_{k}}\right\}_{k \in \mathbb{N}}$ with $\lim _{k \rightarrow \infty} \bar{\alpha}\left(x_{n_{k}}, x^{*}\right)<1$, where $x^{*}$ is the unique fixed point off .

From Case 2 in the proof of Theorem 29, we obtain the following results.

Corollary 32 Let $(X, p)$ be a complete partial metric space and let $f: X \rightarrow X$ be a weakly Kannan contractive mapping. Then the fixed point problem for $f$ is well posed with respect to $p$.

Corollary 33 Let $(X, d)$ be a complete metric space and let $f: X \rightarrow X$ be a weakly Kannan contractive mapping. Then the fixed point problem for $f$ is well posed with respect to $d$.

The next result, whose proof we omit because it follows the same method as in Theorem 29, is an extension of the previous one to the cyclical case.

Theorem 34 Let $(X, p)$ be a complete partial metric space, $A_{1}, \ldots, A_{m}(m \in \mathbb{N})$ be a collection of nonempty subsets of $X$ and $Y \subseteq X$. Let $f: Y \rightarrow Y$ be a mapping satisfying all the requirements in the statement of Theorem 21, then the fixed point problem for $f$ is well posed with respect to $p$ if and only if for every sequence $\left\{x_{n}\right\}_{n \in \mathbb{N}}$ in $Y$ such that $\lim _{n \rightarrow \infty} p\left(x_{n}, f\left(x_{n}\right)\right)=0$, there exists a subsequence $\left\{x_{n_{k}}\right\}_{k \in \mathbb{N}}$ with $\lim _{k \rightarrow \infty} \bar{\alpha}\left(x_{n_{k}}, x^{*}\right)<1$, where $x^{*}$ is the unique fixed point of $f$.

Corollary 35 Let $(X, p)$ be a complete partial metric space and $A_{1}, \ldots, A_{m}(m \in \mathbb{N})$ be a collection of nonempty subsets of $X$ and $Y \subseteq X$. Suppose that $f: Y \rightarrow Y$ is a weakly cyclic contractive mapping. Then the fixed point problem for $f$ is well posed with respect to $p$ if and only iffor every sequence $\left\{x_{n}\right\}_{n \in \mathbb{N}}$ in $Y$ such that $\lim _{n \rightarrow \infty} p\left(x_{n}, f\left(x_{n}\right)\right)=0$, there exists a subsequence $\left\{x_{n_{k}}\right\}_{k \in \mathbb{N}}$ with $\lim _{k \rightarrow \infty} \bar{\alpha}\left(x_{n_{k}}, x^{*}\right)<1$, where $x^{*}$ is the unique fixed point off. 
Corollary 36 Let $(X, p)$ be a complete partial metric space and $A_{1}, \ldots, A_{m}(m \in \mathbb{N})$ be a collection of nonempty subsets of $X$ and $Y \subseteq X$. Suppose that $f: Y \rightarrow Y$ is a weakly cyclic Kannan mapping. Then the fixed point problem for $f$ is well posed with respect to $p$.

Corollary 37 Let $(X, d)$ be a complete metric space and $A_{1}, \ldots, A_{m}(m \in \mathbb{N})$ be a collection of nonempty subsets of $X$ and $Y \subseteq X$. Suppose that $f: Y \rightarrow Y$ is a weakly cyclic contractive mapping. Then the fixed point problem for $f$ is well posed with respect to $d$ if and only iffor every sequence $\left\{x_{n}\right\}_{n \in \mathbb{N}}$ in $Y$ such that $\lim _{n \rightarrow \infty} d\left(x_{n}, f\left(x_{n}\right)\right)=0$, there exists a subsequence $\left\{x_{n_{k}}\right\}_{k \in \mathbb{N}}$ with $\lim _{k \rightarrow \infty} \bar{\alpha}\left(x_{n_{k}}, x^{*}\right)<1$, where $x^{*}$ is the unique fixed point off.

Corollary 38 Let $(X, d)$ be a complete metric space and $A_{1}, \ldots, A_{m}(m \in \mathbb{N})$ be a collection of nonempty subsets of $X$ and $Y \subseteq X$. Suppose that $f: Y \rightarrow Y$ is a weakly cyclic Kannan mapping. Then the fixed point problem for $f$ is well posed with respect to $d$.

On account of [45] (see also [47]), given a metric space $(X, d)$, a mapping $f: X \rightarrow X$ is said to be a good Picard operator if $f$ is a Picard operator such that

$$
\sum_{n=0}^{\infty} d\left(f^{n}(x), f^{n+1}(x)\right)<\infty
$$

for any $x \in X$. Moreover, if $x^{*}$ is the unique fixed point of the good Picard operator $f$ and

$$
\sum_{n=0}^{\infty} d\left(f^{n}(x), x^{*}\right)<\infty
$$

for any $x \in X$, then the mapping $f$ is called a special good Picard operator. Notice that we are assuming that $f^{0}(x)=x$ for all $x \in X$.

Recently, the both preceding notions have been extended to the context of partial metric spaces in [19]. Concretely, given a partial metric space $(X, p)$, a mapping $f: X \rightarrow X$ is said to be a good Picard operator if $f$ is a Picard operator such that

$$
\sum_{n=0}^{\infty} p\left(f^{n}(x), f^{n+1}(x)\right)<\infty
$$

for any $x \in X$. In case $x^{*}$ is the unique fixed point of the good Picard operator $f$ and

$$
\sum_{n=0}^{\infty} p\left(f^{n}(x), x^{*}\right)<\infty
$$

for any $x \in X$, then the mapping $f$ is called a special good Picard operator.

Theorem 39 Let $(X, p)$ be a complete partial metric space and let $f: X \rightarrow X$ be a mapping satisfying all the requirements in the statement of Theorem 15 , then $f$ is a special good Picard operator.

Proof We have to prove that

$$
\sum_{n=0}^{\infty} p\left(f^{n}(x), x^{*}\right)<\infty
$$


for any $x \in X$, where $x^{*}$ is the fixed point of $f$. Let $x \in X$. There is no loss of generality in assuming that $x \neq x^{*}$ and that $f^{n}(x) \neq x^{*}$ for all $n \in \mathbb{N}$.

Now, we show that the following inequality holds:

$$
p\left(f(x), f\left(x^{*}\right)\right) \leq \bar{\alpha}\left(x, x^{*}\right) p\left(x, x^{*}\right) .
$$

We consider the following two cases with this aim:

Case 1. If $M\left(x, x^{*}\right)=p\left(x, x^{*}\right)$, then

$$
p\left(f(x), f\left(x^{*}\right)\right) \leq \bar{\alpha}\left(x, x^{*}\right) p\left(x, x^{*}\right) .
$$

Case 2. If $M\left(x, x^{*}\right)=\frac{1}{2} p(x, f(x))$, then

$$
\begin{aligned}
p\left(f(x), f\left(x^{*}\right)\right) & \leq \frac{\bar{\alpha}\left(x, x^{*}\right)}{2} p(x, f(x)) \\
& \leq \frac{\bar{\alpha}\left(x, x^{*}\right)}{2}\left[p\left(x, x^{*}\right)+p\left(x^{*}, f(x)\right)\right],
\end{aligned}
$$

i.e.,

$$
\begin{aligned}
p\left(f(x), f\left(x^{*}\right)\right) & \leq \frac{\bar{\alpha}\left(x, x^{*}\right)}{2-\bar{\alpha}\left(x, x^{*}\right)} p\left(x, x^{*}\right) \\
& \leq \bar{\alpha}\left(x, x^{*}\right) p\left(x, x^{*}\right) .
\end{aligned}
$$

Therefore, in any case,

$$
p\left(f(x), f\left(x^{*}\right)\right) \leq \bar{\alpha}\left(x, x^{*}\right) p\left(x, x^{*}\right) .
$$

Furthermore, it is easily seen that

$$
p\left(f^{n}(x), x^{*}\right) \leq \bar{\alpha}\left(f^{n-1}(x), x^{*}\right) p\left(f^{n-1}(x), x^{*}\right)
$$

for all $n \in \mathbb{N}$. Since $\lim _{n \rightarrow 0} p\left(f^{n}(x), x^{*}\right)=0$ and

$$
p\left(f^{n}(x), x^{*}\right) \leq p\left(f^{n-1}(x), x^{*}\right) \leq \cdots \leq p\left(x, x^{*}\right),
$$

we have that

$$
\bar{\alpha}\left(f^{n-1}(x), x^{*}\right) \leq \theta\left(r_{n}, r_{1}\right) \leq \theta\left(0, r_{1}\right)
$$

with $r_{n}=p\left(f^{n-1}(x), x^{*}\right)$ for all $n \in \mathbb{N}$.

Since $p\left(f^{n}(x), x^{*}\right) \neq 0$ for all $n \in \mathbb{N}$, we deduce that

$$
p\left(f^{n}(x), x^{*}\right) \leq \theta\left(0, r_{1}\right) p\left(f^{n-1}(x), x^{*}\right)<p\left(f^{n-1}(x), x^{*}\right)
$$

for all $n \in \mathbb{N}$. It follows that

$$
\frac{p\left(f^{n}(x), x^{*}\right)}{p\left(f^{n-1}(x), x^{*}\right)} \leq \theta\left(0, r_{1}\right)<1
$$


for all $n \in \mathbb{N}$. Then by the D'Alembert criterion, we obtain that

$$
\sum_{n=0}^{\infty} p\left(f^{n}(x), x^{*}\right)<\infty
$$

Therefore, $f$ is a special Picard operator.

Corollary 40 Let $(X, p)$ be a complete partial metric space and let $f: X \rightarrow X$ be a weakly contractive mapping, then $f$ is a special good Picard operator.

Corollary 41 Let $(X, p)$ be a complete partial metric space and let $f: X \rightarrow X$ be a weakly Kannan mapping, then $f$ is a special good Picard operator.

Corollary 42 Let $(X, p)$ be a complete metric space and let $f: X \rightarrow X$ be a weakly contractive mapping, then $f$ is a special good Picard operator.

Corollary 43 Let $(X, p)$ be a complete metric space and let $f: X \rightarrow X$ be a weakly Kannan mapping, then $f$ is a special good Picard operator.

The next result is an extension of Theorem 39 to the cyclical case. We omit its proof because it follows the same method as in the aforesaid theorem.

Theorem 44 Let $(X, p)$ be a complete partial metric space, $Y \subseteq X$ and $A_{1}, \ldots, A_{m}(m \in \mathbb{N})$ be a collection of nonempty subsets of $X$. Let $f: Y \rightarrow Y$ be a mapping satisfying all the requirements in the statement of Theorem 21 , then $f$ is a special good Picard operator.

Corollary 45 Let $(X, d)$ be a complete partial metric space and $A_{1}, \ldots, A_{m}(m \in \mathbb{N})$ be a collection of nonempty subsets of $X$ and $Y \subseteq X$. Suppose that $f: Y \rightarrow Y$ is a weakly cyclic contractive mapping. Then $f$ is a special good Picard operator.

Corollary 46 Let $(X, d)$ be a complete partial metric space and $A_{1}, \ldots, A_{m}(m \in \mathbb{N})$ be a collection of nonempty subsets of $X$ and $Y \subseteq X$. Suppose that $f: Y \rightarrow Y$ is a weakly cyclic Kannan mapping. Then $f$ is a special good Picard operator.

Corollary 47 Let $(X, d)$ be a complete metric space and $A_{1}, \ldots, A_{m}(m \in \mathbb{N})$ be a collection of nonempty subsets of $X$ and $Y \subseteq X$. Suppose that $f: Y \rightarrow Y$ is a weakly cyclic contractive mapping. Then $f$ is a special good Picard operator.

Corollary 48 Let $(X, d)$ be a complete metric space and $A_{1}, \ldots, A_{m}(m \in \mathbb{N})$ be a collection of nonempty subsets of $X$ and $Y \subseteq X$. Suppose that $f: Y \rightarrow Y$ is a weakly cyclic Kannan contractive mapping. Then $f$ is a special good Picard operator. 


\section{Author details}

1 Department of Mathematics, Sciences Faculty for Girls, King Abdulaziz University, P.O. Box 4087, Jeddah, 21491, Saudi Arabia. ${ }^{2}$ Department of Mathematics, King Abdulaziz University, P.O. Box 80203, Jeddah, 21859, Saudi Arabia.

${ }^{3}$ Departamento de Ciencias Matemáticas e Informática, Universidad de las Islas Baleares, Ctra. de Valldemossa km. 7.5, Palma de Mallorca, 07122, Spain.

\section{Acknowledgements}

The authors are in debt to the anonymous referees whose comments helped them to improve the final version of this paper. The third author thanks for the support from the Spanish Ministry of Science and Innovation and the Spanish Ministry of Economy and Competitiveness, under Grants MTM2009-12872-C02-0 and MTM2012-37894-C02-01, respectively.

Received: 28 March 2012 Accepted: 25 September 2012 Published: 11 October 2012

\section{References}

1. Kannan, R: Some results on fixed points. Bull. Calcutta Math. Soc. 60, 71-76 (1968)

2. Kirk, WA, Srinivasan, PS, Veeramani, P: Fixed points for mappings satisfying cyclical contractive conditions. Fixed Point Theory 4, 79-89 (2003)

3. Petric, MA: Fixed points and best proximity points theorems for cyclical contractive operators. PhD thesis, North University of Baia Mare, Baia Mare (2011)

4. Petric, MA, Zlatanov, BG: Fixed points theorems of Kannan type for cyclical contractive conditions. In: Proc. of the Anniversary International Conference REMIA 2010, Plodviv, Bulgaria, pp. 187-194 (2010)

5. Matthews, SG: Partial metric topology. Ann. N.Y. Acad. Sci. 728, 183-197 (1994)

6. Matthews, SG: An extensional treatment of lazy data flow deadlock. Theor. Comput. Sci. 151, 195-205 (1995)

7. Romaguera, S, Tirado, P, Valero, O: Complete partial metric spaces have partially metrizable computational models. Int. J. Comput. Math. 89, 284-290 (2012)

8. Romaguera, S, Schellekens, MP, Valero, O: Complexity spaces as quantitative domains of computation. Topol. Appl. $158,853-860(2011)$

9. Seda, AK, Hitzler, P: Generalized distance functions in the theory of computation. Comput. J. 53, $443-464$ (2010)

10. Romaguera, S, Valero, O: Domain theoretic characterizations of quasi-metric completeness in terms of formal balls. Math. Struct. Comput. Sci. 20, 453-472 (2010)

11. Romaguera, S, Valero, O: A quantitative computational model for complete partial metric spaces via formal balls. Math. Struct. Comput. Sci. 19, 541-563 (2009)

12. Heckmann, R: Approximation of metric spaces by partial metric spaces. Appl. Categ. Struct. 7, 71-83 (1999)

13. Romaguera, S, Schellekens, M: Partial metric monoids and semivaluation spaces. Topol. Appl. 153, 948-962 (2005)

14. Escardo, MH: Pcf extended with real numbers. Theor. Comput. Sci. 162, 79-115 (1996)

15. Oltra, S, Romaguera, S, Sánchez Pérez, EA: Bicompleting weightable quasi-metric spaces and partial metric spaces. Rend. Circ. Mat. Palermo 50, 151-162 (2002)

16. Di Bari, C, Vetro, P: Common fixed points for $\psi$-contractions on partial metric spaces. Hacet. J. Math. Stat. (to appear)

17. Nashine, HK, Samet, B, Vetro, C: Fixed point theorems in partially ordered metric spaces and existence results for integral equations. Numer. Funct. Anal. Optim. 33, 1304-1320 (2012)

18. Vetro, F, Radenović, S: Nonlinear $\psi$-quasi-contractions of Ćirić-type in partial metric spaces. Appl. Math. Comput. 219, 1594-1600 (2012)

19. Argarwal, RP, Alghamdi, MA, Shahzad, N: Fixed point theory for cyclic generalized contractions in partial metric spaces. Fixed Point Theory Appl. 2012, 40 (2012). doi:10.1186/1687-1812-2012-40

20. Ilić, D, Pavlović, V, Rakočević, V: Extensions of Zamfirescu theorem to partial metric spaces. Math. Comput. Model. 55, 801-809 (2012)

21. Romaguera, S: Fixed point theorems for generalized contractions on partial metric spaces. Topol. Appl. 159, 194-199 (2012)

22. Aydi, H, Abbas, M, Vetro, C: Partial Hausdorff metric and Nadler's fixed point theorem on partial metric spaces. Topol. Appl. 159, 3234-3242 (2012)

23. Aydi, H, Vetro, C, Sintunavarat, W, Kumam, P: Coincidence and fixed points for contractions and cyclical contractions in partial metric spaces. Fixed Point Theory Appl. 2012, 124 (2012)

24. Paesano, D, Vetro, P: Suzuki's type characterizations of completeness for partial metric spaces and fixed points for partially ordered metric spaces. Topol. Appl. 159, 911-920 (2012)

25. Di Bari, C, Vetro, P: Fixed points for weak $\varphi$-contractions on partial metric spaces. Int. J. Eng. Contemp. Math. Sci. 1 , 5-13 (2011)

26. Karapinar, E: Fixed point theory for cyclic weak $\phi$-contraction. Appl. Math. Lett. 24, 822-825 (2011)

27. Romaguera, S: Matkowski's type theorems for generalized contractions on (ordered) partial metric spaces. Appl. Gen. Topol. 12, 213-220 (2011)

28. Abdeljawad, T, Alzabut, JO, Mukheimer, A, Zaidan, Y: Banach contraction principle for cyclical mappings on partial metric spaces (2011). arXiv:1112.5891v1 [math.GN]

29. Abbas, M, Nazir, T, Romaguera, S: Fixed point results for generalized cyclic contraction mappings in partial metric spaces. Rev. R. Acad. Cienc. Exactas Fís. Nat., Ser. a Mat. (2011). doi:10.1007/s13398-011-0051-5

30. Abdeljawad, T, Karapinar, E, Tas, K: Existence and uniqueness of a common fixed point on partial metric spaces. Appl. Math. Lett. 24, 1900-1904 (2011)

31. Altun, I, Erduran, A: Fixed point theorems for monotone mappings on partial metric spaces. Fixed Point Theory Appl. 2011, Article ID 508730 (2011)

32. Ćirić, L, Samet, B, Aydi, H, Vetro, C: Common fixed points of generalized contractions on partial metric spaces and an application. Appl. Math. Comput. 218, 2398-2406 (2011)

33. Karapinar, E, Erhan, IM: Fixed point theorems for operators on partial metric spaces. Appl. Math. Lett. 24, 1894-1899 (2011) 
34. Karapinar, E: Weak $\phi$-contraction on partial metric spaces and existence of fixed points in partially ordered sets. Math. Aeterna 1, 237-244 (2011)

35. Ilić, D, Pavlović, V, Rakočević, V: Some new extensions of Banach's contraction principle to partial metric space. Appl. Math. Lett. 24, 1326-1330 (2011)

36. Altun, I, Sadarangani, K: Corrigendum to "Generalized contractions on partial metric spaces" [Topology Appl. 157 (2010) 2778-2785]. Topol. Appl. 158, 1738-1740 (2011)

37. Altun, I, Sola, F, Simsek, H: Generalized contractions on partial metric spaces. Topol. Appl. 157, 2778-2785 (2010)

38. Altun, I, Simsek, H: Some fixed points theorems on dualistic partial metric spaces. J. Adv. Math. Stud. 1, 1-8 (2008)

39. Rus, IA: Fixed point theory in partial metric spaces. An. Univ. Vest Timis,. Ser. Mat.-Inform. XLVI, 149-160 (2008)

40. Valero, O: On Banach fixed point theorems for partial metric spaces. Appl. Gen. Topol. 6, 229-240 (2005)

41. Oltra, S, Valero, O: Banach's fixed point theorem for partial metric spaces. Rend. Ist. Mat. Univ. Trieste 36, 17-26 (2004)

42. Dugundji, J, Granas, A: Weakly contractive mappings and elementary domain invariance theorem. Bull. Greek Math. Soc. 19, 141-151 (1978)

43. Ariza-Ruiz, D, Jimenez-Melando, A: A continuation method for weakly Kannan mappings. Fixed Point Theory Appl. 2010, Article ID 321594 (2010)

44. Rus, IA: Picard operators and well-posedness of fixed point problems. Stud. Univ. Babeş-Bolyai, Math. 52, 147-156 (2007)

45. Rus, IA: The theory of a metrical fixed point theorem: theoretical and applicative relevances. Fixed Point Theory 9 , 541-559 (2008)

46. Rus, IA: Cyclic representations and fixed points. Ann. "Tiberiu Popoviciu" Sem. Funct. Equ. Approx. Convexity 3, 171-178 (2005)

47. Păcurar, M, Rus, IA: Fixed point theory for cyclic $\varphi$-contractions. Nonlinear Anal. 72, 1181-1187 (2010)

48. Petruşel, G: Cyclic representations and periodic points. Stud. Univ. Babeş-Bolyai, Math. 5, 107-122 (2005)

49. Petric, MA: Best proximity points theorems for weak cyclic Kannan contractions. Filomat 25, 145-154 (2011)

doi:10.1186/1687-1812-2012-175

Cite this article as: Alghamdi et al.: On fixed point theory in partial metric spaces. Fixed Point Theory and Applications 2012 2012:175.

\section{Submit your manuscript to a SpringerOpen ${ }^{\circ}$ journal and benefit from:}

- Convenient online submission

Rigorous peer review

- Immediate publication on acceptance

- Open access: articles freely available online

- High visibility within the field

- Retaining the copyright to your article 